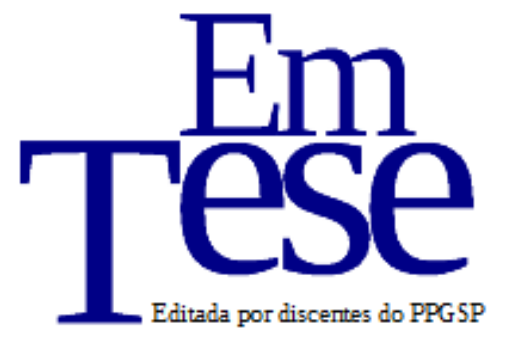

UFSC

\title{
RESENHA
}

\section{Sociologia crítica da educação: olhares cosmopolitas ${ }^{1}$}

Marcelo Pinheiro Cigales ${ }^{2}$ Treicy Giovanella da Silveira ${ }^{3}$

APPLE, Michael, W; BALL, Stephen J; GANDIN, Luís A. (orgs.). Sociologia da Educação: análise internacional. Porto Alegre: Penso, 2013. 456p.

Sociologia da educação: análise internacional é uma coletânea que reúne 37 artigos distribuídos em três partes: a) Perspectivas e teorias; b) Processos e práticas sociais; c) Desigualdades e resistências. Escrito por uma polissêmica e cosmopolita equipe de autores (as) reconhecidos (as) no campo de investigação em Sociologia da Educação, a obra foi organizada pelos professores e pesquisadores Michael Apple, Stephen Ball e Luís Gandin, igualmente reconhecidos por seus trabalhos nas áreas de currículo e políticas educacionais. Michael Apple é professor na Universidade de Wisconsin-Madison (EUA) na escola de educação e entre suas obras de maior destaque nesta área está "Educação e Poder" de 1982 (APPLE), traduzida para o Brasil em 1989 (APPLE). Stephen Ball é professor titular da cátedra de Mannheim de Sociologia da educação da Universidade de Londres. Entre sua produção teórica podemos destacar o livro "Education reform: A critical and post-structural approach" de 1994 (BALL). O terceiro organizador da coletânea é o professor brasileiro de educação Luís Armando Gandin da Faculdade da Educação da Universidade Federal do Rio Grande do Sul (UFRGS). Entre outras obras, foi autor organizador, em parceria com Michael Apple e Wayne Au, do livro "Educação crítica: análise Internacional” (2011).

\footnotetext{
1 Esta obra está licenciada com uma Licença Creative Commons Atribuição 4.0 Internacional.

2 Doutorando no PPGSP da Universidade Federal de Santa Catarina. E-mail: marcelo.cigales@ gmail.com

${ }^{3}$ Doutoranda no PPGSP da Universidade Federal de Santa Catarina. E-mail: treicy.gs@gmail.com
} 
Os trinta e sete artigos que compõem a coletânea são precedidos de uma introdução que assume o compromisso, para além de abrir os textos, de apresentar ao (a) leitor (a) um panorama sobre os pressupostos de uma produção de conhecimento sobre a educação que seja crítica e engajada sem perder em qualidade do debate teórico necessário para tal tarefa. A partir de uma discussão sobre as características do campo de estudo chamado "Sociologia da Educação", são abordadas questões como: suas fronteiras, dinâmicas, interesses, níveis de análise, linhas de difusão e filiação teórica. Como uma proposta de coletânea o livro se depara com a dificuldade de ser demasiado amplo e pouco específico ainda que esteja voltado exclusivamente para a área da Sociologia da Educação. O que demonstra que o próprio campo é tomado por diferentes perspectivas de análise teórica e metodológica do objeto. O livro se sustenta na perspectiva da "Sociologia como um esporte de combate", na defesa de uma abordagem crítica na pesquisa em educação (APPLE, BALL, GANDIN, 2013, p. 22), e na Sociologia da Educação como uma área demarcada por conflitos internos de autoafirmação disciplinar. Isto é clarividente na busca por uma representatividade global de perspectivas de análise, assim como, no posicionamento crítico colocado pelos organizadores da obra no que tange os impactos da economia de mercado na educação e o acirramento das desigualdades de oportunidades colocadas em jogo pelas histórias narradas no livro.

O campo da Sociologia da Educação é descrito com base na noção de uma entrada do pós-colonialismo dentro das ciências sociais, o qual teria por consequência desfazer as barreiras disciplinares com as ciências humanas assim como, trazer um novo olhar, das vozes silenciadas pelo "ocidente de características masculinas e brancas". Da forma como o campo é descrito pelos autores, é possível afirmar que a sociologia da educação não é uma disciplina exclusivamente das Ciências Sociais e pode ser trabalhada por um número mais amplo de pesquisadores. É assumido pelos organizadores o impacto das teorias pós-coloniais na produção de conhecimento sobre a educação dando destaque para as relações de dominação e exploração das quais as instituições escolares fazem parte (APPLE; BALL; GANDIN, 2013, p. 22). A coletânea se afirma como um espaço de construção de conhecimento sobre a Sociologia da Educação com base nos pilares da polissemia, e demarca seu posicionamento crítico perante os desafios das desigualdades da contemporaneidade no que chamam de mundo globalizado. Os anos de estabelecimento da Sociologia da Educação possibilitaram que a disciplina criasse rupturas teóricas e de abordagem metodológica distintas acirrando disputas dentro do próprio campo. Neste sentido, a área da Sociologia da Educação é vista a partir de seus jogos de interesses. Os autores também afirmam que o livro oferece uma 
coletânea de textos com capacidade elucidativa do que chamam de "insights práticos" sobre o que significa fazer e falar sobre sociologia.

Os organizadores da coletânea evidenciam que parte dos autores que integram a coletânea se filiam a perspectiva da análise crítica em educação sendo que, uma das seções tem como foco o próprio engajamento e "muitos dos autores assumem uma posição semelhante ao que Michael Burawoy chamou de 'sociologia orgânica pública'." (APPLE; BALL; GANDÍN, 2013, p. 21-22). Tal postura está relacionada ao próprio desenvolvimento da sociologia da educação e consequentemente a filiação teórica dos organizadores do livro (APPLE, 1989; 2006), que concebem a educação como um projeto de transformação social.

Os organizadores tentam se blindar da crítica de reproduzir uma visão ocidentalizada e anglo-saxã afirmando que reconhecem seu "posicionamento dentro das estruturas de poder do conhecimento" (APPLE; BALL; GANDÍN, 2013, p. 27). Contudo, é inegável que se existisse "um projeto pós-colonial" de construção de conhecimento somente com base nas epistemologias do Sul (SANTOS; MENESES, 2010) por exemplo, este não teria sido alcançado pelo livro, mesmo assim, houve uma atenção por parte dos organizadores de inserir em seus capítulos autores de regiões distintas do globo.

Uma postura crítica pode ser reflexo do próprio desenvolvimento desse campo de pesquisa, já que estudar a educação não é tarefa fácil pelo simples motivo de estarmos - desde muito cedo - envolvidos nesse processo de socialização que não se restringe somente a escola, mas também a (s) família (s), a religião, aos amigos e de forma crescente, aos meios de comunicação. Sendo assim, cabe a todo (a) sociólogo (a) da educação o trabalho intelectual de estranhamento e desnaturalização, e ainda, de se distanciar dessa relação quase intrínseca com o objeto de pesquisa. Por outro lado, estudar a Educação parece ser um problema que sensibiliza os sociólogos engajados, justamente porque é a pedra do mito de Sísifo ${ }^{4}$, ou seja, a pauta de uma educação transformadora é perseguida pelos intelectuais críticos, mas inalcançável na sua plenitude. Em outras palavras, estariam os sociólogos da educação fadados à esperança de um amanhã melhor, sem conseguir ir além da crítica de uma educação que está a serviço dos poderosos? (YOUNG, 2007).

A primeira parte do livro conta com textos de Susan L. Rortson, Inés Dussel, David Gillborn e Gloria Ladson-Billings, Johannah Fahey e Jane Kenway, Meg Maguire, Ursula Hoadley e Johan Muller, Mark Olssen, Neil Selwyn, Roger Slee, Carol Vicent, Philip A.

\footnotetext{
${ }^{4}$ Segundo a mitologia Grega, Sísifo foi condenado a passar a eternidade empurrando uma pedra ao topo de um morro e toda vez que estivesse próximo de atingir seu objetivo a pedra era empurrada para o início da jornada fazendo com o que Sísifo perdesse todo o esforço empregado.
} 
Woods, Deborah Youdell. São apresentadas correntes teóricas que podem ser aproximadas e complementam os estudos da Sociologia da Educação como o feminismo, a Teoria Racial Crítica e a teoria dos códigos. Autores que fazem parte de um movimento pós-estruturalista, ou posteriores a virada linguística, são as bases dos capítulos desta parte como Foucault, Derridad e Judith Butler; outros já consagrados clássicos a exemplo de Weber ou como um forte expoente neste campo da sociologia, Pierre Bourdieu também são contemplados. Conceitos mais específicos tais quais maternagem, espaço, internacionalização de "talentos", conectividade, inclusão, racionalização, poder, entre outros, são mobilizados como forma de mapear e apresentar didaticamente instrumentos teóricos e conceituais para a pesquisa em sociologia da Educação.

A segunda parte tem a colaboração de Michael Apple, Stephen Ball, Bob Lingard, Andrew Brantlinger, Laurel Cooley, Ellen Brantliger, Greg Dimitriadis, John Evans, Brian Davies, Emma Rich, Adam Gamoran, Phillip Brown, Hugh Lauder, Pauline Lipman, Maria Alice Nogueira, António Nóvoa e Boaventura de Souza Santos. Dentre os eixos de análise desta parte do livro é possível destacar as transformações políticas, sociais, econômicas e culturais nas quais se envolvem o processo de escolarização. São abordadas também as mudanças que a educação vem sofrendo da segunda parte do século XX até a primeira década do século XXI, com maior ênfase para este último período. As políticas neoliberais, as transformações culturais acarretadas pela globalização e principalmente pela financeirização do capital são temas que transpassam a maioria dos artigos apresentados nesta seção. Resultado de várias pesquisas recém-concluídas ou em processo de conclusão, poucos artigos são formados apenas por abordagens teóricas, visto que a maioria associou em suas análises dados empíricos sobre determinados espaços e realidades sociais. Além disso, é possível citar a colaboração de uma pesquisadora brasileira (a professora de Sociologia da Educação da UFMG, Maria Alice Nogueira), que somada a outros dois colaboradores (Marília Pontes Sposito, da USP, e Luís Gandín) da coletânea, representam o país nessa análise internacional da sociologia da educação.

A terceira e última parte do livro apresenta os trabalhos de Geetha Nambissan, Kathellen Lynch, Margaret Crean, Marie Moran, Jill Blackmore, Pat Thomson, Agnés Zanten, Ramón Flecha, Luís Armando Gandín, Kris Gutiérrez, Arshad Ali, Cecilia Henríquez, Grace Livingston, Louise Morley, Diane Reay, Marília Pontes Sposito e Lois Weis. Entre as principais categorias apresentadas destacam-se: gênero, classes sociais, juventude e o estudo das elites. Nesse sentido, entre os eixos de pesquisa apresentados nessa seção está a desigualdade de acesso ao ensino superior entre as classes sociais e a abordagem de gênero, 
reflexo da disparidade de oportunidades e reconhecimento entre homens e mulheres. Também são apontadas as estratégias educacionais da classe dominante e sua consequente facilidade de acesso e continuidade em relação ao sistema educacional, que da mesma forma é visto como fruto dessa desigualdade. Por outro lado, também é apresentada a realidade das classes populares, e alguns cenários de transformações em relação ao processo educacional em comunidades carentes em distintos cenários empíricos. Nesse sentido, as camadas mais pobres possuem capacidade de organização e resistência ao sistema que tende a privilegiar apenas uma parcela da população, os pertencentes às classes econômicas mais elevadas.

Sociologia da educação: análise internacional constitui-se numa coletânea relevante para a área de estudos da sociologia crítica em educação por ter o mérito de apresentar uma série de estudos que resultaram de pesquisas teóricas e empíricas fruto do trabalho de diversos professores/pesquisadores envolvidos com a temática. Ressalta-se, que a amplitude da obra fez com que os temas fossem tratados de forma geral, sem análises profundas de cenários específicos, talvez essa seja a principal crítica à coletânea, pois evidenciar múltiplos cenários culturais, políticos e sociais distintos sob o olhar da sociologia crítica da educação teve o objetivo de lançar luz sobre aspectos que aparentemente estão interligados e agindo sobre a mesma força: os interesses de uma economia de mercado.

A multiplicidade de olhares no interior do campo de pesquisa da sociologia da educação a partir dos anos 1970 gerou, consequentemente, novos espaços de discussão, além do tratamento teórico e metodológico do processo educativo. Este não se restringe apenas aos espaços formais de escolarização, é preciso analisar os diferentes espaços sociais ou campos (BOURDIEU, 1989; 2004) em que os diversos agentes lutam pelo monopólio legítimo do discurso sobre o social e todos os demais trunfos que isso resulta. Mais que mercadoria, a educação é poder, como bem salientou um dos organizadores da coletânea em outro momento (APPLE, 1989).

Embora a obra intitule-se uma análise internacional, é necessário ressaltar que o eixo geográfico privilegiado gira em torno dos centros de pesquisa localizados nos Estados Unidos e Reino Unido. Ainda que presentes, são poucos os autores que contribuem na coletânea advindos dos países ditos "emergentes" e quase nenhuma colaboração de autores dos países africanos e asiáticos. Nesse sentido, ainda que a obra tenha um caráter crítico em sociologia da educação é necessário ressaltar o enquadramento geográfico, político e teórico que suas discussões e cenários empíricos nos apresentam.

Por fim, estas críticas em nada desmerecem o esforço dos organizadores e a originalidade dos seus colaboradores - que indubitavelmente são referência nas diversas 
temáticas de pesquisa que a sociologia da educação se debruça - mas antes, espera ser um convite a todas (os) interessadas (os) nos estudos e pesquisas que possuem como foco à educação. 


\section{Referências}

APPLE, M. (Org.); AU, W. (Org.); GANDIN, L. A. (Org.) . Educação Crítica: análise internacional. Porto Alegre: ArtMed, 2011. v. 1. 548 p .

APPLE, Michael. W; BALL, S. J; GANDIN, L. A. (orgs.). Sociologia da Educação: análise internacional. Porto Alegre: Penso, 2013a. 456p.

; ___ _ _ _ (orgs.). Mapeamento da sociologia da educação: contexto social, poder e conhecimento (Introdução). In: Sociologia da Educação: análise internacional. Porto Alegre: Penso, 2013b. p. 17-29.

APPLE, Michael W. Education and power. Nova York: Routledge, 1982.

1989. . Educação e poder. Trad. de Maria Cristina Monteiro. Porto Alegre: Artes Médicas, . W. Ideologia e Currículo. 3. ed. Porto Alegre: Artmed, 2006.

. W. Educação e Poder. Porto Alegre: Artmed, 1989.

BALL, Stephen. Education Reform: A Critical and Post-structural Approach. Buckingham: Open University Press. 1994.

BOURDIEU, Pierre. O poder simbólico. Trad. Fernando Tomaz. Rio de Janeiro: Bertrand Brasil, 1989.

. Os usos sociais da Ciência: por uma sociologia clínica do campo científico. Trad. Denise Barbara Catani. São Paulo: UNESP, 2004.

SANTOS, Boaventura de Sousa; MENESES, Maria Paula. (Orgs.) Epistemologias do Sul. São Paulo; Editora Cortez. 2010. 637p.

YONG, M. Para que servem as escolas? Educação e Sociedade. Campinas, vol. 28, n. 101, p. 1287-1302, set./dez. 2007.

Recebido em 10-01-2017;

Revisado em 27-07-2018;

Publicação em 15-12-2018. 